\title{
AN EVALUATION OF THE FLIPPED-LEARNING PEDAGOGICAL APPROACH
}

He Rourou, Volume 1, Issue 1, 32-48, 2021

DEVENDER CHENDRI

\section{ABSTRACT}

In recent years the emerging possibilities in the education system are flexibility (Nuhoğlu et al., 2020) and self-paced learning (Priscila, 2020). The flexibility of studying anywhere and anytime can provide opportunities for learners to achieve their educational goals. A self-paced and customized learning environment could enhance the learning experience of the students. This research evaluates flipped-learning pedagogical approaches for year 13 Maths students. Quantitative and qualitative data collection methods track and monitor students' academic outcomes. The findings suggest that flipped-learning improved students' academic achievement and progress. Additionally, students who missed the lessons could understand the concept and complete learning activities before coming to the next lesson. A flipped-learning approach has encouraged the students to make them responsible for their learning, bringing questions to the classroom to extend their conceptual understanding, and develop mathematical reasoning and thinking skills.

\section{INTRODUCTION}

A shift of flexible and self-paced learning is underway in the education system, and the pace of change is mandating smarter methods with an emphasis on teaching to learning. However, the emerging challenges such as the demand to learn anytime, anywhere at your own pace are shifting gears towards the use of technology that caters to different learning styles. Indeed, due to the covid-19 situation during the lockdown period, this researcher has scheduled Zoom online sessions for teaching and learning. Students who are turning up for these sessions enjoy this new paradigm in their education. However, this approach partially addresses the challenges because the students have to be available online to understand the lesson.

To overcome this, the study of Yoshida (2016) reveals that the requirements of flipped-learning are where the learners are expected to study at home and do collaborative learning in class, autonomously take responsibility for their learning, and personalized education. Hence, these emerging challenges motivated this researcher to come up with a solution and provide a flexible platform for the learners to continue learning at their own pace.

This research was carried out at a school where there are several initiatives to raise student achievement and progress. In recent years the school arranged professional development programs for teachers to focus on "Visible Learning" (Hattie, 2012) and "Teaching to the NorthEast" (Bishop, 2019). 
Hattie (2012) states that visible learning and teaching means making teaching visible to students to know what to do and how to do it, and learning visible to the teachers so that they know whether learning is occurring or not. In successful classrooms, visible learning occurs when the learning goals are explicit and challenging, learners become their own teachers, teachers become learners of their own teaching, teacher-student relationships, teachers provide feedback, and set high expectations for students. Bishop (2019) found that teaching to the North-East promotes learning for everyone and envisages increasing equity in the education system by responding to diverse groups of students that consign learners prior knowledge, indigenous, culture and language, students with learning difficulties, and any other unique qualities they bring to the classroom rather than being seen as barriers in their learning. Thus, the purpose of this research is to evaluate the impact of the flipped-learning pedagogical approach on "Visible Learning" and "Teaching to the North-East".

\section{LITERATURE REVIEW}

\section{Flipped Learning}

The definition of flipping the classroom by Maciejewski (2015) is shifting the content instruction out of class time by posting relevant online videos for students to understand on their own and assigning in-class time for conceptual practice, one-on-one and group discussions to reinforce interactive student engagement, achievement, and meet the learning needs of the students. Similarly, Yoshida (2016) defines flipped-learning as the process that learners go through a blending of direct-instruction with constructivist-learning to become skilled at the subject contents.

\section{Flipped-Learning as a Pedagogy}

Bishop and Verleger (2013) emphasize that the flipped-learning classroom approach is a technology-supported pedagogy because of the direct video-based individual instructional approach outside the classroom and interactive small-group learning activities inside the classroom.

Similarly, Francl (2014) states that flipped learning pedagogy appears to decrease the workload because of the elimination of in-class instruction time about the topic. Instead, the teacher facilitates in-class time for individual, small-group, and whole-class discussions and learning activities and reviewing the pieces of the automated instructional video where appropriate to support the learning. The teacher's workload is changing from an explainer to a responsiveknowledge provider by automating the instruction through videos, enabling self-pacing instruction based on learners response, facilitating to view the online resources on any device at any time and anywhere, setting up an online task for students to explore themselves, encouraging the learners to watch the instructional video out of class time and complete their homework in-class time, either individually or in small groups, conducting in-class discussions about the concept, and testing learners retention and understanding with formal assessments. Bishop and Verleger (2013) highlight that various pedagogies such as problem-based learning, cooperativelearning can be used to enhance the design of flipped-learning as a pedagogy.

A Hancock, Shepherd, Lawrence \& Zubrick (2013) study reveals that attendance matters for academic achievement and progress and highlights that as absence rates of the learners increase, their educational achievement continues to decline. In contrast, Harmon (2017) highlights that flipped learning helps students to catch up either at home or once they are back at school, and 
the students who do not have access to the internet or devices at home could use school devices to watch the required information to carry on with the task. The videos developed for flippedlearning must have a good image and sound quality, and a variety of online approaches for the learners to catch up on the missed lessons, meet the learning outcomes and curriculum standards. Additionally, the flipped instruction refers to moving the teaching aspects into the homework environment, differentiated teaching to meet individual learning needs, allows more time to work collaboratively in the classroom, and promotes high-level thinking among the students.

Lo \& Hew (2017) found that using a flipped-learning approach, the impact on student performance was significantly improved compared to the traditional-teaching approach. Interestingly, Bhagat, Chang, \& Chang (2016) study reveals that using a flipped-learning approach, low-achievers performed better. In contrast, the average and high-achievers performance remained the same when compared to the traditional teacher-centered approach. In contrast, the study of Gundlach et al. (2015) critique that using a traditional-teaching had an impact on student performance was significantly better than the flipped-learning approach.

\section{Main Benefits and Key Challenges}

The study of Mayer, Fiorella, \& Stull (2020) states that the students learn better with the teacher creating instructional videos as they will be on the screen instructor with innovative graphics and the delivering content contains engaging and summarizing resourceful explanations. The other benefits include preparing the learners for in-class discussion, understand the concept before coming to the class, promotes on-demand learning, flexibility to watch and re-watch the videos if they have any questions, enabling learners to self-manage and take ownership of their own learning, extending teacher reach outside the classroom including the learners who are unable to attend the class and in need of extra time for their learning.

The three challenges of implementing flipped learning approach are student-related, teacher, and operational (Lo \& Hew, 2017). Firstly, the student-related challenges are not being familiar with the routines, could not focus on watching videos, needed more precise instructions for in-class activities, increased workload because of pre-class activities at home, and out-of-class support such as could not ask questions immediately while watching the videos. Secondly, the teacher challenges are not entirely familiar with this instructional approach and increased workload for preparing videos and online learning materials. Lastly, the operational challenges are students computing resources at home - may not have internet access to watch the videos, monitoring students outside the class - challenging to ensure that the student has watched the video, teachers computing skills to incorporate flipped learning, and availability of well equipped IT resources to support this new learning.

To overcome some of these challenges, Taffard (2020) states that open-ended questions do not have one specific answer; instead, there will be many possible answers and can be solved in multiple ways and on different levels. Therefore, incorporating open-ended questioning helps learners develop reasoning skills and make mathematical decisions, and teachers listen to learners' thinking and then prompt and probe where necessary. Additionally, the research of Neely (2019) outlines that an effective way to challenge the learners and make them learn better and think more is the usage of open-ended questions.

The depth of knowledge (DOK) matrix of Robert (2015) distinguishes between cognitively demanding DOK levels ( 1 to 4 ) that feature open-ended questions. For instance, calculate an area and perimeter: a) Level 1 recall question - "Find the perimeter of a rectangle that measures 8 units 
by 4 units". b) Level 2 skill/concept question - "List the measurements of three different rectangles that each has a perimeter of 20 units". c) Level 3 strategic thinking question - "What is the greatest area you can make with a rectangle that has a perimeter of 24 units". d) Level 4 extended thinking question relates to create, analyze, connect, critique, design, apply, prove, and synthesize.

Moreover, the swift evolution of technology and its implementation creates gaps in recent literature regarding the application of flipped-learning instructional pedagogy, online open-ended questions, and educational outcomes. Hence, to fill this gap, the present research evaluates the impact of flipped-learning approaches on mathematics concepts for Year 13 students in a secondary school.

\section{RESEARCH QUESTIONS}

The main objective of this research is to develop a flipped-learning environment by creating instructional videos with interactive online content to enhance learner-driven education. Furthermore, creating own instructional videos helps personalize and customize learning content to meet individual learning needs based on learner's profiles in the classroom and New Zealand Mathematics Curriculum levels.

Research Question 1 (RQ1):

What is the impact of flipped-learning as a pedagogy on students' academic achievement?

Research Question 2 (RQ2):

What factors contribute to students' progress using flipped-learning pedagogical approaches?

\section{METHODOLOGY}

\section{Action Research and Inquiry Framework}

The Action-Research methodology process takes place gradually and intends to have both appropriate research and action outcomes. Moreover, it is a cyclic, qualitative, participative, reflective, and responsive approach to the emerging needs of the learners (Bob, 2020). 


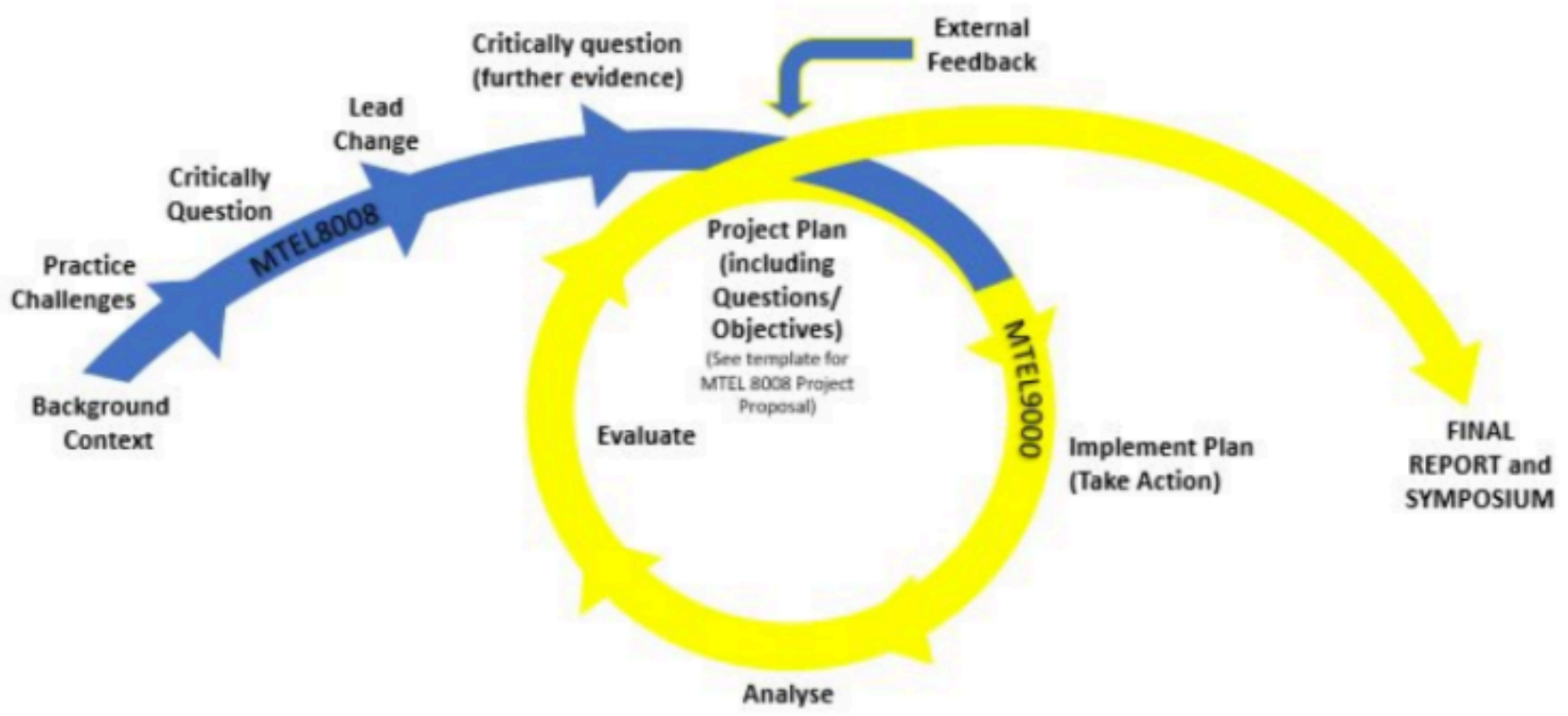

Figure 1. MTEL Teacher Inquiry Framework V.1.0

Within this, the MTEL teacher inquiry framework has been selected as an appropriate method to research because it allows the researcher to go through an iterative process of taking action, analyzing, and evaluating. Therefore, there may be several iterations during the implementation of this project. To determine the success of the flipped-learning, the researcher has decided on a mixed-methods approach to data collection Wisdom and Creswell (2013) highlights that: a) mixedmethods approach helps to understand contradictions between the results of the quantitative approach and the findings of the qualitative approach, b) give a voice to study and reflect on participants point of view, c) provides methodological flexibility and adaptable, d) collects rich and comprehensive data, and e) compare and validate findings, and creates a concrete foundation for drawing conclusions.

The main stakeholders are all students from the researcher's Year 13 maths class who will participate in flipped-learning activities as their regular lessons. Furthermore, the three stages of incorporating flipped-learning approaches such as Pre-Class, In-Class, and Post-Class, allow the researcher to reflect on the teaching practice for every lesson, analyze and address learning needs and evaluate the outcome of this approach.

\section{Flipped-Learning Pedagogy Intervention}

Pre-Class: The researcher has created own instructional videos and open-ended questions by using the Screencast-o-matics, Lucidchart, Geogebra, and NZGrapher apps as these tools were very effective for collaborating in real-time, accelerating understanding with powerful diagramming and data visualization, and helps to work from anywhere by using automation features to diagram faster and see mathematical ideas in a whole new light. The content in the videos was interactive and incorporated dynamic graphical representation, and this learning approach has enhanced students' visual conceptualization; moreover, teaching these kinds of concepts on the board would be difficult. Therefore, this researcher has planned, prepared, and presented ten flipped-learning lessons. All the materials relevant to the concept were posted on Google Classroom a day before the actual flipped-learning lesson to prepare for class. All students are expected to watch this instructional video and answer the open-ended question before coming to the class. This approach will shift the content instruction out of class time, and the learners are anticipated to study at home autonomously. 
In-Class: The researcher aimed to prepare the students to demonstrate the concept by setting up the instructional videos, open-ended questions, flipped-learning score-points sheet, and Google Forms to fill in the student's voice. Additionally, the score-points sheet shared with students contains a maximum of four points and explained how they could achieve these points for each flipped-learning lesson as follows: 1 point for discussion about the video, 1 point for discussion about the open-ended question, 1 point for demonstrating leadership and collaboration, and 1 point for answering an open-ended question.

The lesson starts with a bit of discourse about the concept. Then, all students will spend more time learning collaboratively in the classroom by participating in conceptual practice, small group and whole-class discussions, and learning activities to reinforce student achievement. The researcher will have more time to reach every student and meet the individual learning needs and review the pieces of an automated instructional video to support the learning. The students who could not attend the lesson can still work collaboratively online with their group members, classmates, and teachers.

During the flipped-learning collaboration, students' names in groups were written on the board, got them to discuss their understanding of the concept from the video, and then wrote up their responses. Then asked the students to understand the open-ended question, discuss it in groups, and then again write up their responses on the board about their approach to the problem. Subsequently, the whole class review took place by putting what they all said altogether and coconstructed a plan to know what they should do next from those responses written on the board. Following this, at the end of the lesson, the students were informed about the score points they achieved for the lesson based on their participation.

Post-Class: Finally, to know the learners' flipped-learning experience, an exit slip was created on google forms and sent to all Year 13 Maths class students at the end of each flipped-learning lesson.

\section{DATA COLLECTION METHODS}

According to Hattie (2012), one of the tools to understand student achievement and progress is effect-size. The effect-size measures the impact of teaching and learning approaches on student achievement and determines the efficacy of an educational intervention relative to a comparison approach. Two sets of data are required to calculate the effect-size. If the value of effect-size is positive, the intervention has an increased effect on achievement. Similarly, if the value of effect-size is negative, the intervention has a decreased effect on achievement. Using effectsizes benefits teachers to estimate student progress and re-evaluate instructional pedagogy to customize learning for individuals and groups of students.

Subsequently, the innovation of the VLPAT (Visible Learning Progress and Achievement Tool) graph by Hattie (2012) measures individual student progress and achievement. It outlines that the $\mathrm{x}$-axis represents "student-progress" or effect size, and the $\mathrm{y}$-axis represents "studentachievement" or score. 1) The first quadrant (Q1 - upper right-hand corner) of the graph, where both $\mathrm{x}$ and $\mathrm{y}$-axis are positive, identifies learners with high progress and high achievement. 2) The second quadrant (Q2 - upper left-hand corner) of the graph, where the $\mathrm{x}$-axis is negative and the $\mathrm{y}$ axis is positive, identifies learners with low progress and high achievement. 3) The third quadrant (lower left-hand corner) of the graph, where both the $\mathrm{x}$ and $\mathrm{y}$-axis are negative, identifies learners with low progress and low achievement. 4) The fourth quadrant (lower right-hand corner) of the 
graph, where the $\mathrm{x}$-axis is positive, and the $\mathrm{y}$-axis is negative, identifies learners with high progress and low achievement.

Similarly, the research of Bishop (2019) highlights that teaching to the North-East enhances "High Teaching Skills and High Relationships" with the learners like an extended family-like context (Whānau) that puts relational leadership at the center of learning and leads to develop both culturally responsive and sustaining teaching practice.

Indeed, Bishop (2019) study states that effective teachers are positioned in Q1 with "High Teaching skills and High Relationships" is a metaphor of Hattie (2012) study where learning is highly visible in Q1 with "High Progress and High Achievement."

Hence, the analysis of the data collected will determine the impact of flipped-learning pedagogy in terms of visible learning quadrants such as Q1, Q2, Q3, Q4, and teaching to the north-east (Q1), north-west (Q2), south-west (Q3), south-east (Q4).

In addition the Education Perfect (EP) online learning platform is based on the core concepts of self-paced learning, provides learners with personalized learning, offers flexibility to learn anytime, anywhere, and gamification to improve student engagement (Education Perfect, 2020). $\mathrm{EP}$ is an innovative and creative tool that builds efficacy in independent learners. Moreover, the students who were using the Education Perfect tool for their learning outperformed in NZQA national pilot online maths assessment program (Education Perfect, 2020).

During the implementation stage of this project, two approaches such as "conventional pedagogy" followed by "flipped-learning as a pedagogy," have been applied.

The following methods were used to address RQ1 and RQ2:

Conventional Pedagogy: Initially, all students from Year 13 Maths class participated in a "conventional pedagogy" approach. This researcher taught the concept AS 3.2 Linear Programming using standard methods; then, this researcher conducted a test and collected the score points (out of 40 ).

Flipped-Learning Pedagogy: Following this, all students from the same Year 13 Maths class participated in a "flipped-learning pedagogy" approach. This researcher taught the concepts AS 3.4 Critical Path and AS 3.8 Time Series using flipped-learning methods, conducted 10 tests where students can score a maximum of 4 points in each test, and then collected the overall score points (out of 40).

VLPAT Analysis: Then, the score points of these two approaches were recorded and compared using the Visible Learning Progress and Achievement Tool (VLPAT) to calculate the effect-size and display the outcome of each student's achievement and progress on the graph. Hence, the outcome and effect-size value for all students from Year 13 Maths class will determine the success of flipped-learning as a pedagogy.

Education Perfect (EP) Analysis: The EP tool evaluates the impact of flipped-learning pedagogy to determine the individual student and overall class achievement and progress based on the comparison of the pretest conventional-pedagogy and post-test flipped-learning pedagogy score points.

Absent Work Analysis: The absent students' data has been collected from each flipped-learning 
lesson to evaluate whether the learners should still catch up on the lesson by watching the instructional videos to understand the concept and complete open-ended tasks before coming to the next class.

\section{ANALYSIS, FINDINGS, AND RESULTS}

This section focuses on results and findings of VLPAT analysis, EP analysis, and Absent Work analysis to evaluate the impact of the flipped-learning pedagogical approach on student academic achievement and progress and factors contributing to them.

\section{VLPAT Analysis}

According to Lalongo (2016), the effect size is a measure for quantifying the difference between the same groups or two different groups over time on a common scale, and effect size help in measuring both learners' achievement improvement for a group of students and variation of learner performances expressed on a standardized scale.

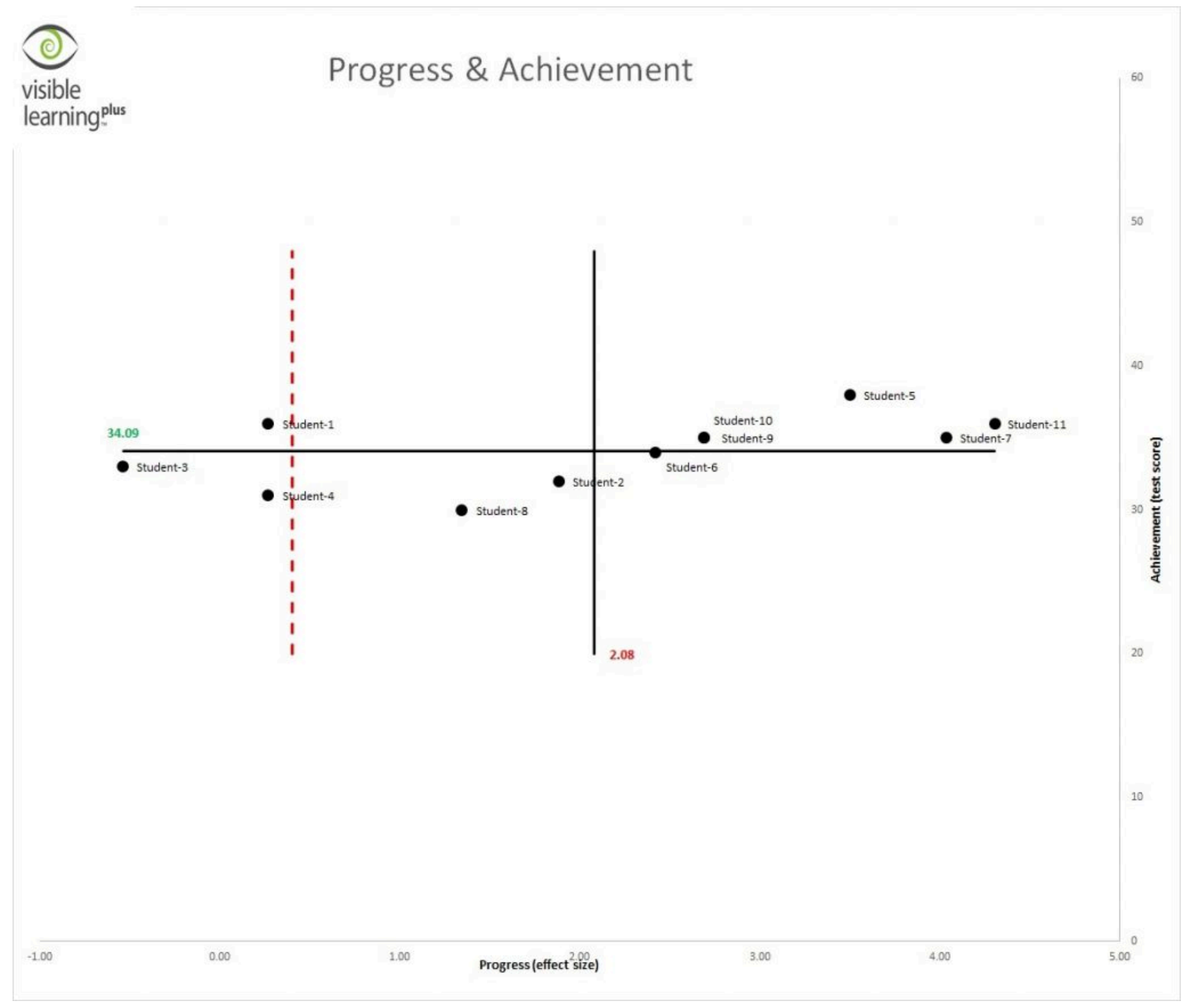

Figure 2. Visible Learning Progress \& Achievement Tool (VLPAT) Graph

In the VLPAT graph (Figure 2), the $\mathrm{x}$-axis represents "Student Progress (Effect Size)," and the $\mathrm{y}$ - axis represents "Student Achievement (Score Points)." The VLPAT graph has generated all students' academic achievement on average is 34.09 out of 40 score points (85.2\%), and academic progress on average is 2.08 effect size. According to Hattie (2012), the average effect-size is 0.4, 
considered the Hinge-Point. Therefore, if the effect size is less than the hinge-point (0.4), student academic progress occurs below the average, effect-size between 0.4 and 0.6 to be considered above average, and effect-size above 0.6 to be considered excellent. Thus, the impact of flippedlearning as a pedagogy on overall students' progress is excellent with effect-size 2.08, and students' achievement is $85.2 \%$. Additionally, TKI (2019) states that an effect size of above 0.4 would show that innovation is working more than expected in a classroom setting. Table 1 highlights the calulation for effect size.

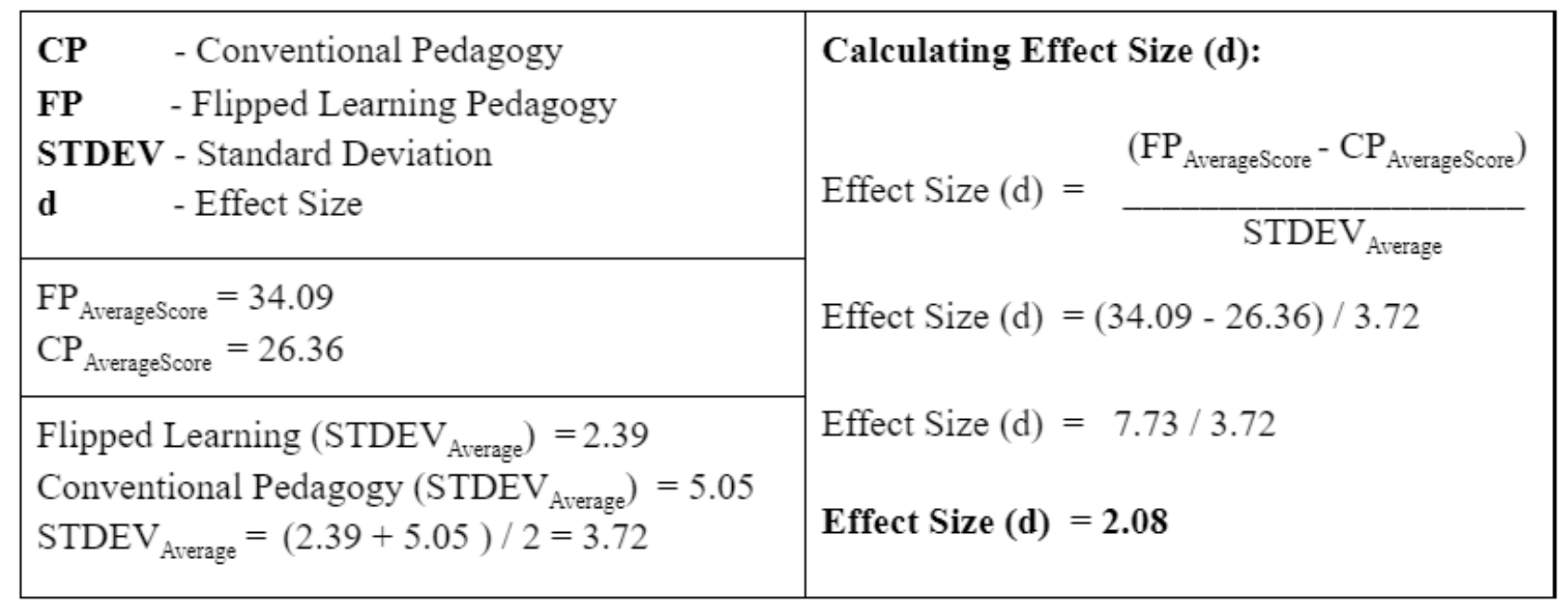

Table 1. Calculation of effect size

\begin{tabular}{|c|c|c|c|}
\hline Student & Conventional - & Flipped-Learning & Effect size $>$ \\
\hline Student-1 & 35 & 36 & 0.27 \\
\hline Student-2 & 25 & 32 & 1.88 \\
\hline Student-3 & 35 & 33 & -0.54 \\
\hline Student-4 & 30 & 31 & 0.27 \\
\hline Student-5 & 25 & 38 & 3.50 \\
\hline Student- 6 & 25 & 34 & 2.42 \\
\hline Student-7 & 20 & 35 & 4.04 \\
\hline Student-8 & 25 & 30 & 1.35 \\
\hline Student-9 & 25 & 35 & 2.69 \\
\hline Student-10 & 25 & 35 & 2.69 \\
\hline Student-11 & 20 & 36 & 4.31 \\
\hline Average & 26.36 & 34.09 & 2.08 \\
\hline STDEV & 5.05 & 2.39 & \\
\hline AV Stdev & & 3.72 & \\
\hline
\end{tabular}

Table 2. Score Points Out of 40

Additionally, an evaluation of flipped-learning pedagogy with year 13 maths learners revealed in Table 3 that the student academic progress is recorded highest for "Student - 11" with 4.31 effectsize and lowest for "Student - 3" with -0.54 effect-size, whereas the student academic achievement is recorded highest for "Student - 5" with score points 95\% and lowest for "Student - 8" with 75\%. 


\begin{tabular}{|l|l|}
\hline Second Quadrant (Q2) & First Quadrant (Q1) \\
X-Axis: Low Progress (Effect Size) & X-Axis: High Progress (Effect Size) \\
Y-Axis: High Achievement (Score Points) & Y-Axis: High Achievement (Score Points) \\
& Student-11 $(4.31,36) \quad$ Student-9 $(2.69,35))$ \\
Student-1 $(0.27,36)$ & Student-7 $(4.04,35) \quad$ Student-10 $(2.69,35)$ \\
& Student-5 $(3.50,38) \quad$ Student-6 $(2.42,34)$ \\
\hline Third Quadrant $($ Q3) & Fourth Quadrant $($ Q4) \\
X-Axis: Low Progress (Effect Size) & X-Axis: High Progress (Effect Size) \\
Y-Axis: Low Achievement (Score Points) & Y-Axis: Low Achievement (Score Points) \\
& \\
Student-4 $(0.27,31)$ & Student-2 $(1.88,32)$ \\
Student-3 $(-0.54,33)$ & Student-8 $(1.35,30)$ \\
& \\
\hline
\end{tabular}

Table 3. The Impact on Student Academic Achievement and Progress

In Figure 2, the VLPAT graph, four quadrants determine the students' academic progress and achievement. The results are summarised in Table 3. First Quadrant Q1: The students with high progress and high achievement belong to Q1, and they are as follows: 1) "Student - 11" with effect size 4.31 and score points 90\%. 2) "Student - 7" with effect size 4.04 and score points 88\%. 3) "Student - 5" with effect size 3.50 and score points 95\%. 4) "Student - 9" with effect size 2.69 and score points $88 \% .5$ ) "Student - 10" with effect size 2.69 and score points $88 \%$. 6) "Student - 6" with effect size 2.42 and score points $85 \%$.

Second Quadrant Q2: The students with low progress and high achievement belong to Q2, and he is "Student - 1" with effect-size 0.27 and score points 90\%. Third Quadrant Q3: The students with low progress and low achievement belong to Q3, and they are as follows: 1) "Student - 4" with effect size 0.27 and score points $78 \%$. 2) "Student - 3" with effect size -0.54 and score points 83\%. Fourth Quadrant Q4: The students with high progress and low achievement belong to Q4, and they are as follows: 1) "Student - 2" with effect size 1.88 and score points $80 \%$. 2) "Student 8 " with effect size 1.35 and score points $75 \%$.

Indeed Bishop (2019) study states that effective teachers are positioned in Q1 (teaching to the north-east) with "High Teaching skills and High Relationships" with the learners is a metaphor of Hattie (2012) study where learning is highly visible in Q1 (High Progress and High Achievement). 


\section{North-East Teaching}

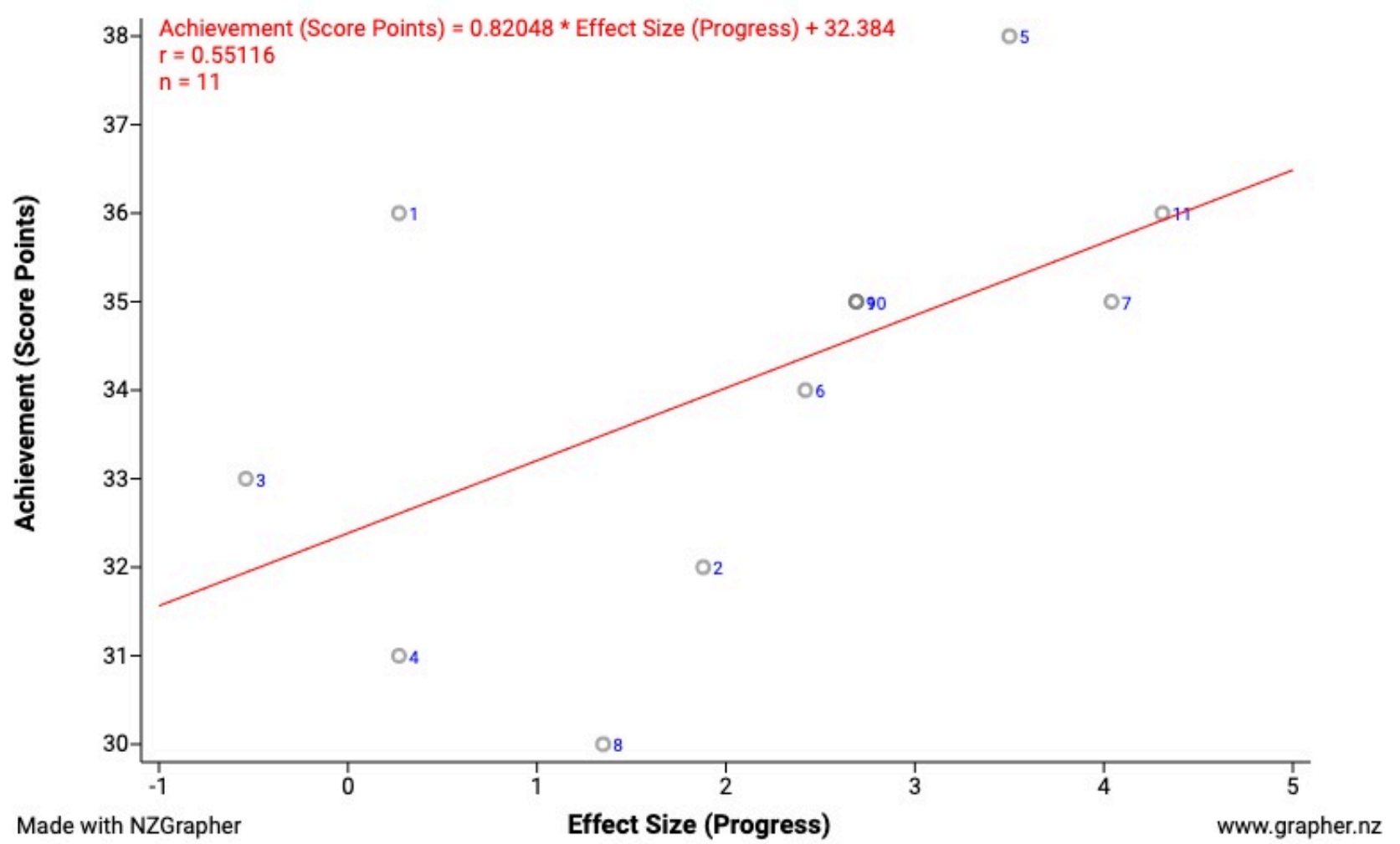

Figure 3. Teaching to the North-East Graph

Thus, the "Teaching to the North-East" graph has been generated using the NZGrapher tool, see Figure 3. The red line clearly shows that the impact of flipped-learning pedagogy is positive, and moving towards north-east Q1 puts relational leadership at the center of learning to raise students' academic achievement and progress.

\section{EP Analysis}

Figure 4 show an evaluation of flipped-learning pedagogy using the Education Perfect (EP) tool. This resulted in 19.3\% academic improvement on average for all year 13 maths students compared to conventional pedagogy. In saying this, the average academic outcome of conventional pedagogy is $65.9 \%$, whereas flipped-learning pedagogy is $85.2 \%$.

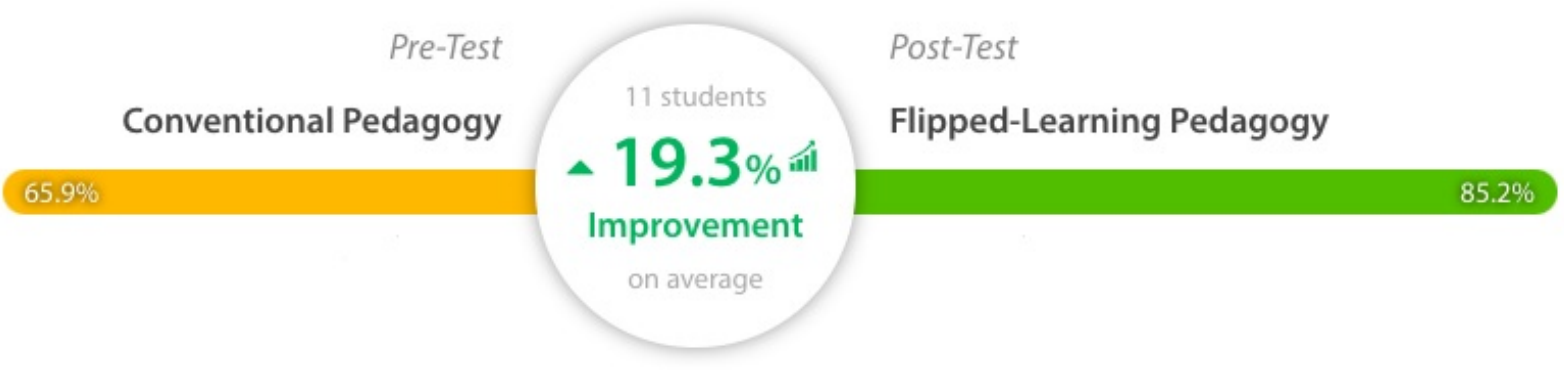

Figure 4. Overall Flipped Learning Improvement on Average

Additionally, the student academic improvement using flipped-learning is recorded highest for "Student - 11" with 40\% and lowest for "Student - 3" with $-5 \%$, as shown in Table 4. Furthermore, summary statistics and graphs of year 13 maths students show that using flipped-learning pedagogy improves students' academic achievement and progress. Thus, low and average- 
achieving students will struggle to reach their full potential if there is no flipped-learning pedagogical approach in place.

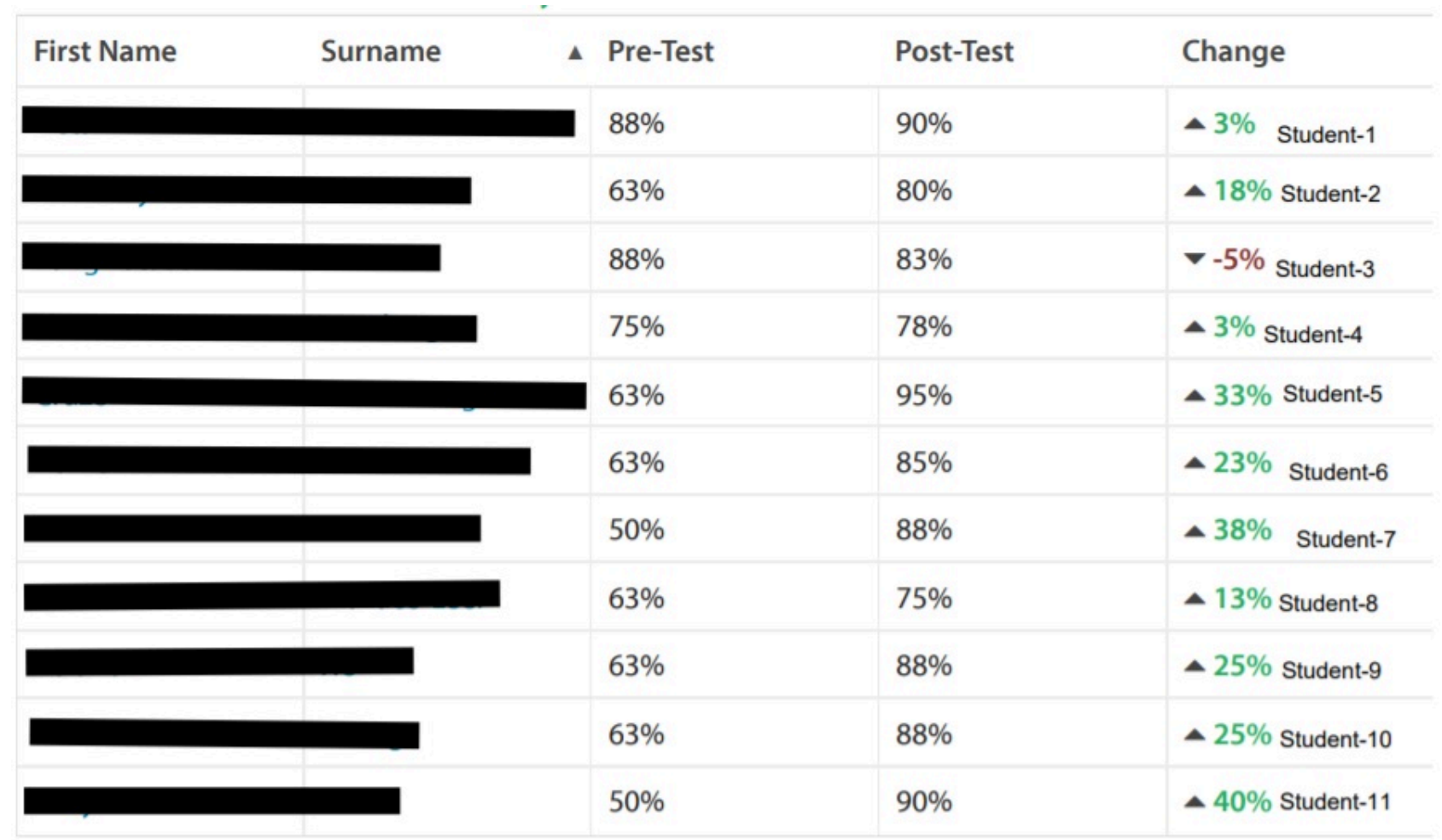

Table 4. Individual Student Flipped Learning Improvement on Average

According to Melville (2019), the biggest challenge of being a teacher is balancing teacher time in the class; therefore, tools such as Education Perfect (EP) help teachers to be more effective, efficient, and responsive to the students' requirements. Similarly, Cabi (2018) study states that the results of flipped learning environments revealed that using mathematics software, digital content, and instructional videos doubled the learners' academic progress and facilitated learning by visualizing mathematics content that enhanced permanent learning.

\section{Absent Work Analysis}

Table 5 shows the list of absent students for each flipped-learning lesson and also displays whether each absent student has completed the tasks or not. The tasks include watching the instructional video, understanding and answering open-ended questions, and collaborating with other students and the teacher. 


\begin{tabular}{|c|c|c|c|c|c|c|c|}
\hline \multirow[b]{2}{*}{ Flipped-Learning } & \multirow[b]{2}{*}{ Absent Students } & \multicolumn{2}{|c|}{ Tasks Completed } & \multirow[b]{2}{*}{ Flipped-Learning } & \multirow[b]{2}{*}{ Absent Students } & \multicolumn{2}{|c|}{ Tasks Completed } \\
\hline & & YES & No & & & YES & NO \\
\hline 1 & 1) Student-11 & Yes & - & 6 & 1) Student- 2 & - & No \\
\hline \multirow{4}{*}{2} & 1) Student-1 & Yes & - & \multirow{3}{*}{7} & 1) Student-4 & Yes & - \\
\hline & 2) Student-4 & Yes & - & & 2) Student-6 & Yes & - \\
\hline & 3) Student-8 & Yes & - & & 3) Student-7 & Yes & - \\
\hline & 4) Student-11 & Yes & - & \multirow{4}{*}{8} & 1) Student-2 & Yes & - \\
\hline \multirow{5}{*}{3} & 1) Student-1 & Yes & - & & 2) Student-4 & Yes & - \\
\hline & 2) Student-4 & Yes & - & & 3) Student- 6 & Yes & - \\
\hline & 3) Student- 6 & Yes & - & & 4) Student-7 & Yes & - \\
\hline & 4) Student-8 & - & No & \multirow{4}{*}{9} & 1) Student-2 & Yes & - \\
\hline & 5) Student-10 & Yes & - & & 2) Student-4 & Yes & - \\
\hline \multirow{5}{*}{4} & 1) Student-2 & Yes & - & & 3) Student- 6 & Yes & - \\
\hline & 2) Student-7 & Yes & - & & 4) Student-7 & Yes & - \\
\hline & 3) Student-9 & Yes & - & \multirow{6}{*}{10} & 1) Student-1 & Yes & - \\
\hline & 4) Student-10 & Yes & - & & 2) Student-2 & $\cdot$ & No \\
\hline & 5) Student-11 & Yes & - & & 3) Student-3 & - & No \\
\hline \multirow{6}{*}{5} & 1) Student-1 & Yes & - & & 4) Student-4 & - & No \\
\hline & 2) Student-2 & Yes & - & & 5) Student-8 & - & No \\
\hline & 3) Student-5 & Yes & - & & 6) Student-9 & Yes & \\
\hline & 4) Student-9 & Yes & - & \multicolumn{2}{|c|}{ Total Students Tasks Completed (Yes/No) } & 33 & 6 \\
\hline & 5) Student-10 & Yes & - & \multicolumn{2}{|c|}{ Overall Students } & \multicolumn{2}{|c|}{39} \\
\hline & 6) Student-11 & Yes & - & \multicolumn{2}{|c|}{ Tasks Completed Percentage (Yes/No) } & $84.60 \%$ & $15.40 \%$ \\
\hline
\end{tabular}

Table 5. Absent Students Work Analysis

The results of absent work analysis show that 33 out of 39 students who were absent for the ten flipped-learning lessons were able to successfully catch up on the lessons they missed by watching the instructional videos from home in their own time, understanding the concept, and completing open-ended tasks. Thus, the impact of the flipped-learning pedagogical approach on year 13 maths students who were absent was $84.6 \%$ successful in completing their work before coming to the next lesson. Furthermore, overall 39 students missed 10 flipped-learning lessons, which means, on average, 3.9 students (approximately 4 students) were absent for each flipped-learning lesson. Hence, this indicates that about 4 students in each lesson and may not be the same students in every lesson will struggle to establish the link with the previous lesson if there is no flippedlearning pedagogical approach in place.

\section{CONCLUSION AND RECOMMENDATIONS}

This research report, however, makes several noteworthy contributions to the flipped-learning approaches. The significant findings from the flipped-learning collaborations revealed the factors that contributed to students' progress are as follows: a) Instructional videos were very clear with concise instructions and easy to understand the concept, flexibility to catch up on the lesson anytime anywhere for those who were absent, able to revisit the lesson when students had any questions and have more information than a teacher can do on the board or in the classroom. b) Open-ended tasks allowed the students to develop their ideas with multiple correct answers and apply in-depth curriculum knowledge by working at their own pace, in multiple ways, and at different levels. c) Leadership and collaboration met individual learning needs by reaching every student in every lesson, catching up with the absent students, allowed sharing ideas in small groups and with the whole class, and hearing different views of discussions to find the solution, enhanced the faster way to learn the concepts, encouraged learners participation and gave more control on the learning process.

The results of the VLPAT analysis show that the learning is visible and teaching is to the northeast, the impact of flipped-learning as a pedagogy on overall students progress is strong with effect-size 2.08, and students academic achievement is $85.2 \%$. Additionally, the student academic progress is recorded highest for "Student - 11" with 4.31 effect-size and lowest for "Student - 3" 
with -0.54 effect-size, whereas the student academic achievement is recorded highest for "Student - 5" with score points 95\% and lowest for "Student - 8" with 75\%. The outcomes of EP Analysis have resulted in $19.3 \%$ academic improvement on average compared to conventional pedagogy. Furthermore, the student academic improvement using flipped-learning is recorded highest for "Student - 11" with 40\% and lowest for "Student - 3" with -5\%. The Absent Work Analysis highlights that $84.6 \%$ of absent students could successfully catch up on the lessons they missed because of flipped-learning pedagogy. Therefore, using a flipped-learning pedagogical approach significantly improved student academic achievement and progress than the conventional teaching approach. However, in-depth evaluation highlights that the low and average achievers performed better using a flipped-learning approach, whereas the high-achievers academic outcomes remained nearly the same.

Future research could include incorporating Edpuzzle in the instructional videos to add more dynamic open-ended tasks. This technique will make the video lessons more interactive and encourage students to self-paced learning. Similarly, Baker (2016) studies found that EdPuzzle is an excellent tool for teachers who use flipped-learning pedagogical approaches because it offers interactive features such as open-ended questions students answered in the instructional video and helps redefine learning.

\section{LIMITATIONS}

This researcher acknowledges there are some limitations, such as comparability of the data collected. For example, although the topics taught using conventional pedagogy and flippedlearning approach were equivalent in terms of difficulty and at the same level based on NCEA Year 13 curriculum standards, perhaps collecting the data from the same number of tests (eg. 10 tests - Conventional Pedagogy and 10 tests - Flipped-learning) would have been more credible. For example, in this research, the data collected (scores) from the flipped-learning approach comprises 10 tests ( 4 marks each test) that totals up to 40 marks. Whereas the data collected (scores) from the conventional pedagogy was from one 40 marks test, instead of collecting data from 10 tests (4 marks each test) could have resulted in more reliable and valid data.

\section{REFERENCES}

Baker, A. (2016). EdPuzzle | Online Tools for Teaching \& Learning. Active Learning with Interactive Videos: Creating Student-Guided Learning Materials. Journal of Library es Information Services in Distance Learning, 1-9. Retrieved October 14, 2020, from https://blogs.umass.edu/onlinetools/assessment-centered-tools/edpuzzle/

Bhagat, K. K., Chang, C. N., \& Chang, C. Y. (2016). The Impact of the Flipped Classroom on Mathematics Concept Learning in High School. Journal of Educational Technology er Society, 19(3), 134-142. http://www.jstor.org/stable/jeductechsoci.19.3.134

Bishop, R. (2019). Teaching to the North-East. New Zealand Council for Educational Research. https://www.nzcer.org.nz/nzcerpress/books/teaching-north-east

Bishop, J. L., \& Verleger, M. A. (2013). The flipped classroom: a survey of the research [Conference presentation]. The 120th ASEE National Conference and Exposition, Atlanta, GA (Paper ID 6219). Washington, DC. American Society for Engineering Education. https://peer.asee.org/ the-flipped-classroom-a-survey-of-the-research 
Bob, D. (2020). Beginners' guide to action research - Resource papers in action research. http://www.aral.com.au/resources/guide.html

Cabi, E. (2018). View of The Impact of the Flipped Classroom Model on Students' Academic Achievement. International Review of Research in Open and Distributed Learning, 19(3). http://www.irrodl.org/index.php/irrodl/article/view/3482/4647

Credforce (2020). Education 4.0: Rise of Flexible Learning in the 'New World'. Retrieved August 19, 2021. https://www.credforce.com/spotlight/article/education-4-rise-of-flexible-learning-inthe-new-world

Education Perfect (2020). How does online learning impact results in national assessments? Retrieved June 20, 2021. https://www.educationperfect.com/wp-content/uploads/2020/11/EP-NZQAAnalysis.pdf

Francl, T. J. (2014). Is Flipped Learning Appropriate? Journal of Research in Innovative Teaching, 7(1), 119-128. https://www.nu.edu/wp-content/uploads/2018/11/journal-of-research-ininnovative-teaching-volume-7.pdf

Gundlach, E., Richards, K. A. R., Nelson, D., \& Levesque-Bristol, C. (2015). A comparison of student attitudes, statistical reasoning, performance, and perceptions for web-augmented traditional, fully online, and flipped sections of a statistical literacy class. Journal of Statistics Education, 23(1), 1-33. https://doi.org/10.1080/10691898.2015.11889723

Harmon, W. (2017). Instructional Strategies - How to use Flipped Learning to Support Absent Students. Retrieved October 14, 2020, from https://theartofeducation.edu/2017/07/31/use-flippedlearning-support-absent-students/

Hancock, K., Shepherd, C., Lawrence, D., \& Zubrick, S. (2013). Student Attendance and Educational Outcomes: Every Day Counts. http://doi.org/10.13140/2.1.4956.6728

Hattie, J. (2012). Visible learning for teachers: Maximizing impact on learning. Routledge/Taylor \& Francis Group.

Lalongo C. (2016). Understanding the effect size and its measures. Biochemia medica, 26(2), 150-163. https://doi.org/10.11613/BM.2016.015

Lo, C \& Hew, K. (2017). A critical review of flipped classroom challenges in K-12 education: Possible solutions and recommendations for future research. Research and Practice in Technology Enhanced Learning. 12. 1-22. https://doi.org/10.1186/s41039-016-0044-2

Mayer, R.E., Fiorella, L. \& Stull, A. (2020). Five ways to increase the effectiveness of instructional video. Education Tech Research Dev, 68, 837-852 (2020). https://doi.org/10.1007/ s11423-020-09749-6

Maciejewski, W. (2015). Flipping the calculus classroom: An evaluative study. Teaching Mathematics and its Applications. 35(4). https://doi.org/10.1093/teamat/hrv019

Melville, B. (2019). New look, same core focus for Education Perfect. Otago Daily Times. Retrieved October 14, 2020, from https://www.odt.co.nz/business/new-look-same-core-focuseducation-perfect 
Neely, C. (2019). Using Open-Ended Questions in the Classroom. Retrieved October 08, 2020, from http://info.teachstone.com/blog/open-ended-questions-in-the-classroom

Nuhoğlu Kibar, P., Gündüz, A. Y., \& Akkoyunlu, B. (2020). Implementing Bring Your Own Device (BYOD) Model in Flipped Learning: Advantages and Challenges. Technology, Knowledge and Learning, 25(3), 465-478. https://doi.org/10.1007/s10758-019-09427-4

Priscila (2020). What is self-paced learning? Meaning explained. Retrieved August 19, 2021, from https://www.easy-lms.com/help/lms-knowledge-center/self-paced-learning-definition/ item 10384

Robert, K. (2015). Is Depth of Knowledge Complex or Complicated? Retrieved April 13, 2020, from https://robertkaplinsky.com/is-depth-of-knowledge-complex-or-complicated/

Taffard, K. (2020). "Good” (Open-ended) Questions. Retrieved from https://docs.google.com/ presentation/d/1nmYWw2tRpZbG_2rxeLaApgV3WhX8cEtTS3vh44bNw7g/ edit\#slide=id.g62ac6111ce_0_494

TKI (2019). Effect size / Concepts / Working with data / Using evidence for learning. Retrieved October 14, 2020, from https://assessment.tki.org.nz/Using-evidence-for-learning/Working-withdata/Concepts/Effect-size

Wisdom, J., \& Creswell, J. (2013). Mixed Methods: Integrating Quantitative and Qualitative Data Collection and Analysis While Studying Patient-Centered Medical Home Models. Rockville, MD: Agency for Healthcare Research and Quality. February 2013. AHRQ Publication No. 13-0028-EF. Retrieved from https://pcmh.ahrq.gov/sites/default/files/attachments/ MixedMethods_032513comp.pdf

Yoshida, H. (2016). Perceived Usefulness of "Flipped Learning" on Instructional Design for Elementary and Secondary Education: With Focus on Pre-service Teacher Education. International Journal of Information and Education Technology. 6. 430-434. https://doi.org/10.7763/ IJIET.2016.V6.727

The opinions expressed are those of the paper author(s) and not He Rourou or The Mind Lab.

He Rourou by The Mind Lab is licensed under a Creative Commons Attribution-NonCommercial-ShareAlike 4.0 International License, except where otherwise noted. [ISSN 2744-7421] 


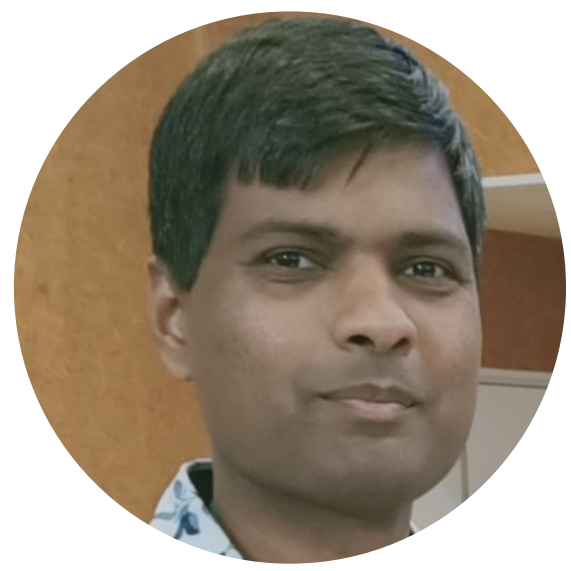

Devender Chendri

On the surface, Devender Chendri is an accomplished Apple Certified teacher with experience teaching Mathematics and Digital Technologies in secondary schools. For him, serving in the education sector is one of the noblest ways to serve the community. He is currently working as a Teacher of Mathematics at Southern Cross Campus and lives in Auckland. His research interests include digital pedagogies, collaborative teaching, virtual classroom environment, flipped learning, cross-curriculum, and future-focused education. He graduated from the Auckland University of Technology with a Master's degree in Service-Oriented Computing (Honors First Class) and from the Mindlab with another Master's Degree in Teaching and Education Leadership. He is a professional member of the Auckland Mathematics Association (AMA) and New Zealand Association of Mathematics Teachers (NZAMT).

Contact Details: $\underline{\text { dchendri01@gmail.com }}$ 